\title{
Penerapan Pelapis Dinding Kawat Ayam di Desa Koto Marapak Kabupaten Padang Pariaman
}

\author{
Zulfira Mirani' ${ }^{1}$ Monika Natalia*2, Yan Partawijaya ${ }^{3}$, Mafriyal $^{4}$, Riswandi $^{5}$ \\ 1,2,3,4,5 Jurusan Teknik Sipil, Politeknik Negeri Padang \\ *e-mail: raninawaf@gmail.com, monikanatalia75@gmail.com, yan_parta21@yahoo.com
}

\begin{abstract}
Earthquake-safe house, the costs not expensive. We can eliminate earthquake damage by strengthening our house while paying attention the rules of structure. Use chicken wire reinforcement. Chicken wire reinforcement can strengthen the walls by wrapping. Chicken wire can also be used to strengthen practical columns as well as ring beams. And to improve the connection between practical column structural elements with ring beams and wall to column anchoring. Result is to be help the residents of Koto Marapak Village in Padang Pariaman to provide counseling and training to strengthen their homes so that they are earthquake resistant with economical costs. Because this area is very earthquake-prone. The method applied by conducting counseling, field surveys as well as discussions with community leaders, pilot / training (which is guided by the discovery team) that together with the community members work together to provide reinforcement of houses that are earthquake resistant.
\end{abstract}

Keywords: earthquake, house, chicken wire reinforcement, Koto Marapak

\begin{abstract}
Abstrak
Untuk menghasilkan bangunan rumah tinggal sederhana aman gempa pada dasarnya biaya yang harus dikeluarkan tidak selalu dalam jumlah yang besar. Kita dapat mengeliminir kerusakan pasca gempa dengan terlebih dahulu melakukan perkuatan terhadap bangunan rumah tinggal kita dengan tetap memperhatikan kaidah struktur yang harus ada dari suatu bangunan sederhana. Salah satunya adalah dengan penggunaan kawat ayam. Kawat ayam ini dapat memperkuat dinding dengan cara membalut dinding bangunan tersebut. Kawat ayam juga dapat digunakan untuk memperkuat kolom praktis serta balok ring. Serta untuk memperbaiki sambungan antara elemen struktur kolom praktis dengan balok ring serta penjangkaran dinding ke kolom. Tujuan yang ingin dicapai dari kegiatan pengabdian ini adalah dapat membantu warga Desa Koto Marapak di Kabupaten Pariaman untuk memberikan penyuluhan dan pelatihan perkuatan rumah tinggal mereka sehingga tahan gempa dengan biaya yang ekonomis. Karena daerah ini sangat rawan gempa. Metode yang diterapkan dengan melakukan penyuluhan, survey lapangan serta diskusi dengan pemuka masyarakat, percontohan/pelatihan (yang dipandu oleh tim pengadian) yaitu bersama-sama warga masyarakat bergotong royong dalam memberikan perkuatan rumah tinggal yang tahan gempa.
\end{abstract}

Kata kunci: gempa, rumah tinggal, perkuatan kawat ayam, Koto Marapak

\section{PENDAHULUAN}

\subsection{Latar Belakang}

Desa Koto Marapak di Kabupaten Padang Pariaman merupakan daerah yang berada di dekat 3 daerah yang amblas pada gempa 2009. Desa Koto Marapak berjarak lebih kurang $65 \mathrm{~km}$ dari Kota Padang. Desa Koto Marapak terdiri dari sekitar 190 dan pada umumnya rumah tinggal di desa ini masih merupakan rumah tinggal yang sangat sederhana yang dibangun tanpa ada perkuatan untuk menahan gempa. Sebagian besar masyarakat desa mempunyai mata pencarian bertani dan berkebun. Untuk membuat rumah tinggal tahan gempa, masyarakat desa mengira akan membutuhkan biaya yang besar dan harus membongkar rumah mereka. Perkuatan yang dilakukan terhadap bangunan rumah tinggal sederhana ini antara lain : 1). Mengelilingi / membalut dinding bangunan tanpa perkuatan dengan kawat ayam; 2). Membuat kolom praktis serta balok ring pada bangunan; 3). Melakukan perbaikan pada sambungan antara elemen struktur kolom praktis dengan balok ring serta penjangkaran dinding ke kolom (Boen T, 2012). 


\subsection{Rumusan Masalah}

1. Kondisi rumah tinggal masyarakat Desa Koto Marapak pada umumnya masih kondisi sangat standar tanpa ada perkuatan gempa meskipun mereka tinggal di daerah paling rawan gempa.

2. Selama ini, masyarakat mengira pembangunan rumah tinggal yang tahan gempa membutuhkan biaya yang mahal.

3. Masyarakat tidak mengetahui kaidah-kaidah struktur yang dapat diterapkan pada perbaikan dan pembangunan rumah tinggal.

4. Selama ini belum ada informasi tentang perkuatan rumah tinggal tahan gempa dengan alternatif biaya murah.

5. Dibutuhkan tenaga trampil dari akademisi untuk memberikan masukan dan contoh perkuatan rumah tinggal tahan gempa dengan biaya yang jauh lebih murah yaitu dengan memasang kawat ayam.

1.3. Tujuan

1. Memberikan pengetahuan dan penjelasan mengenai bangunan rumah tinggal yang tidak memenuhi kaidah struktur.

2. Memberikan penyuluhan tentang perbaikan rumah tinggal sederhana yang mengalami kerusakan akibat gempa.

3. Memberikan penyuluhan dan percontohan perkuatan rumah tinggal terhadap gempa dengan memasang kawat ayam.

1.4. Manfaat

1. Masyarakat menyadari bahwa untuk perkuatan bangunan rumah tinggal tidak harus mengeluarkan biaya yang mahal, bisa menggunakan sumber alam yang ada di daerah tersebut yaitu kawat anyam.

2. Dengan dilakukannya perkuatan bangunan akan memperkecil dampak/akibat dari gempa bumi.

3. Dengan adanya keterampilan (skill) tentang Pelapis Dinding dengan menggunakan Kawat Ayam, sangat diharapkan nantinya masyarakat Desa Koto Marapak dapat memperkuat/memperbaiki rumah tinggal mereka agar dapat meminimalisir dampak yang ditimbulkan jika terjadi gempa.

\section{METODE}

Metode pelaksanaan yang dilakukan sebagai berikut :

1. Melakukan survey lapangan. Adapun data dikumpulkan melalui :

- Wawancara, untuk mendapatkan data dari beberapa masyarakat dan pemuka masyarakat atau Wali Korong . Dari wawancara tersebut diperoleh informasi bahwa di daerahnya pada saat terjadi gempa, banyak terjadi kerusakan bangunan rumah tinggal, sedangkan bantuan dari pemerintah tidak mencukupi. Selama ini, masyarakat Desa Koto Marapak tidak mengetahui metode/cara untuk perkuatan rumah tinggal yang tahan gempa karena memang belum pernah ada penyuluhan baik dari pemerintah, praktisi dan kalangan akademisi. Masyarakat Desa Koto Marapak tidak megetahui kaidah standar struktur yang aman dan kokoh terhadap gempa. Mereka membangun rumah tinggal hanya berdasarkan pengalaman turun temurun. Rumah tinggal dengan perkuatan terhadap beban gempa selama ini dianggap membutuhkan biaya yang berkali lipat.

- Observasi lapangan. Dengan melakukan pengamatan langsung melihat keadaan rumah tinggal penduduk di Desa Koto Marapak serta besarnya motivasi dan keinginan masyarakat untuk mengusahakan perkuatan rumah tinggal yang tahan gempa dengan biaya yang jauh lebih ekonomis.

2. Melakukan diskusi sesama tim juga diskusi dengan tim pengarah dari lembaga pengabdian masyarakat Politeknik Negeri Padang. 
3. Melakukan Penyuluhan dan Demonstrasi, cara penggunaan kawat ayam untuk pelapis dinding dan perkuatan rumah tinggal sederhana tahan gempa.

4. Bahan dan alat:

Tabel 1. Bahan

\begin{tabular}{cl}
\hline No & \multicolumn{1}{c}{ Bahan } \\
\hline 1 & Kawat dengan diameter $>1 \mathrm{~mm}$ \\
2 & Kawat Pengikat \\
3 & Pasir \\
4 & Semen \\
5 & Paku Beton \\
6 & Kerikil \\
7 & Besi diameter $8 \mathrm{~mm}$ \\
8 & Besi diameter 10 $\mathrm{mm}$ \\
9 & Batu bata \\
10 & Kayu/Bambu \\
11 & Dan lain-lain \\
\hline
\end{tabular}

Tabel 2. Peralatan

\begin{tabular}{cl}
\hline No & \multicolumn{1}{c}{ Peralatan } \\
\hline 1 & Palu \\
2 & Tang \\
3 & Pita Ukur \\
4 & Kikir Kayu / Sugu Kayu \\
5 & Gerobak \\
6 & Sendok Spesi \\
7 & Gergaji Besi \\
8 & Gergaji Kayu \\
9 & Sekop \\
10 & Cangkul \\
11 & Keranjang \\
12 & Sendok Spesi \\
13 & Alat Bor Beton \\
14 & Tangga \\
15 & Dan lain-lain \\
\hline
\end{tabular}

5. Metode Penerapan Pelapis Dinding dengan Kawat Ayam untuk Perkuatan Rumah Tinggal Sederhana Tahan Gempa (Miran Z, 2014), yaitu :

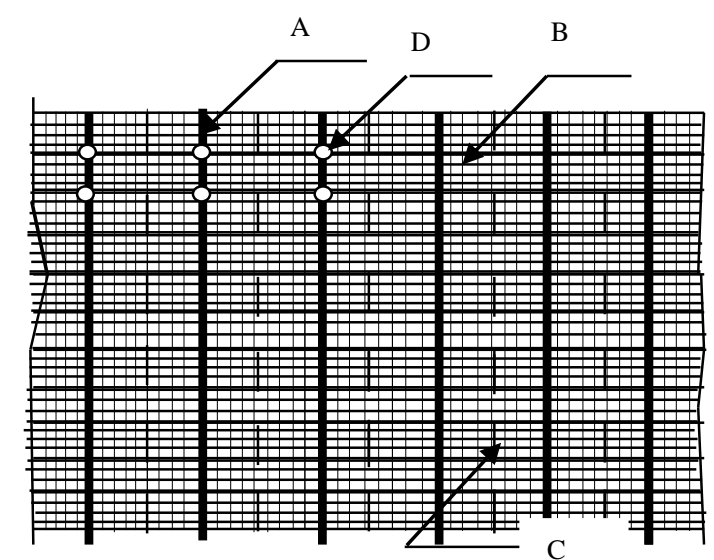

Gambar 1. Seluruh sisi dinding dilapisi dengan kawat ayam (seluruh sisi dinding dibuka plesterannya) 


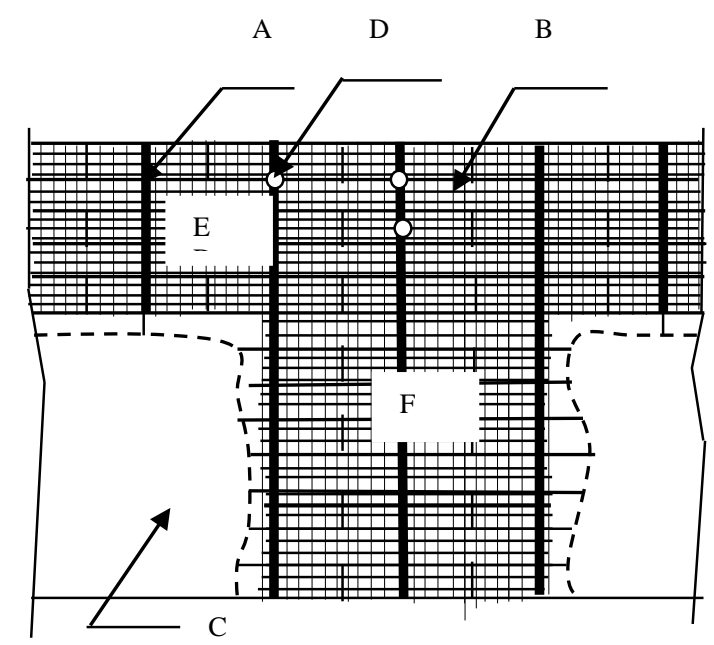

Gambar 2. Sisi dinding yang dilapisi kawat ayam horizontal (E) dan vertical (F) (bagian dinding yang dibuka plesterannya)

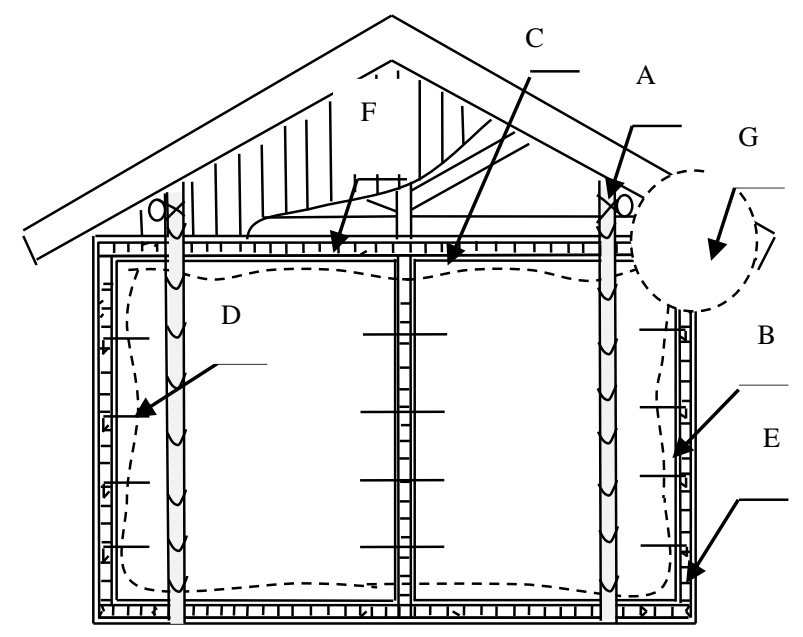

Gambar 3. Potongan Rumah tinggal sederhana yang akan ditambahkan kolom praktis dan balok ring.

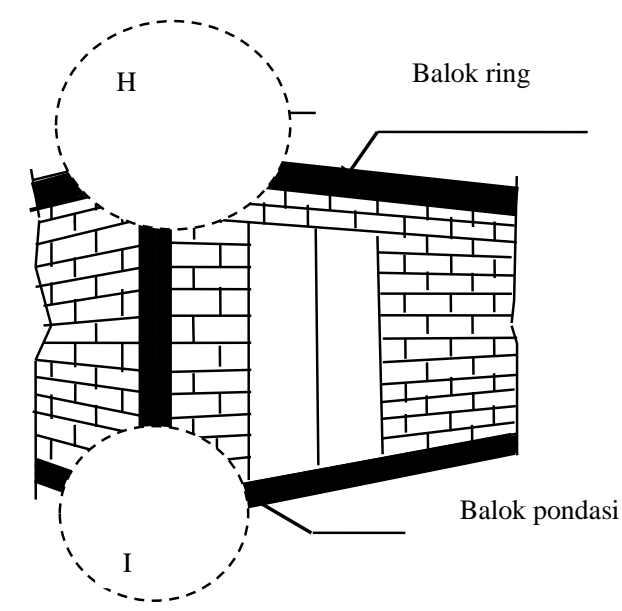

Gambar 4. Lokasi pemasangan jangkar ( H,I) 


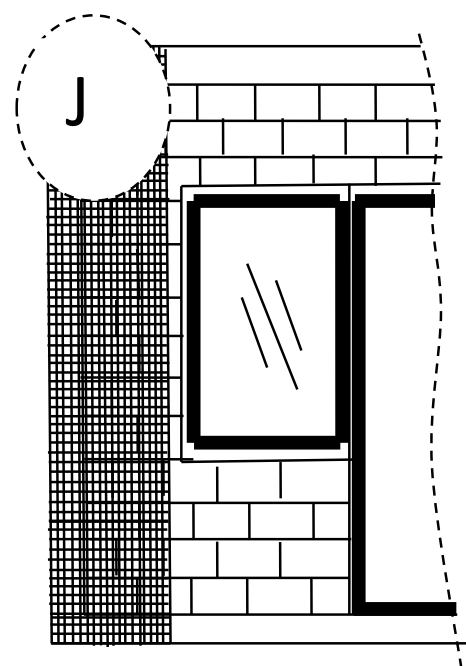

Gambar 5. Kawat ayam sebagai pengganti jangkar dinding ke kolom

\section{HASIL DAN PEMBAHASAN}

Kegiatan pengabdian masyarakat ini menghasilkan penerapan pemasangan kawat ayam pada rumah tinggal masyarakat. Produknya adalah sebuah rumah sederhana yang tahan gempa. Dengan adanya kegiatan ini juga diharapkan masyarakat Desa Koto Marapak dapat memperkuat/memperbaiki rumah tinggal mereka agar dapat meminimalisir dampak yang ditimbulkan jika terjadi gempa. Pada akhirnya masyarakat mempunyai pengetahuan, wawasan dan ketrampilan tentang rumah yang aman gempa, pengerjaanya tidak sulit, biaya pun tidak mahal.

Kegiatan ini sangat didukung oleh masyarakat, hal ini dapat dilihat dari :

a. Masyarakat berpatisipasi aktif dalam diskusi dan proses pelatihan yang diadakan dalam rangka untuk menambah wawasan ataupun mengubah pola pikir masyarakat yang alamiah menjadi ilmu pengetahuan dan teknologi.

b. Memberikan dukungan dengan menginformasikan kendala dan persoalan yang dihadapi mereka selama dalam proses pelapis dinding untuk perkuatan rumah tinggal tahan gempa dengan menggunakan kawat ayam.

c. Memberikan informasi tentang hasil Penggunaan Kawat Ayam sebagai Pelapis Dinding untuk Perkuatan Rumah Tinggal Sederhana Tahan Gempa, apakah sudah dapat dimanfaatkan oleh masyarakat lain atau belum.

Pelaksanaan kegiatan sebagai berikut :

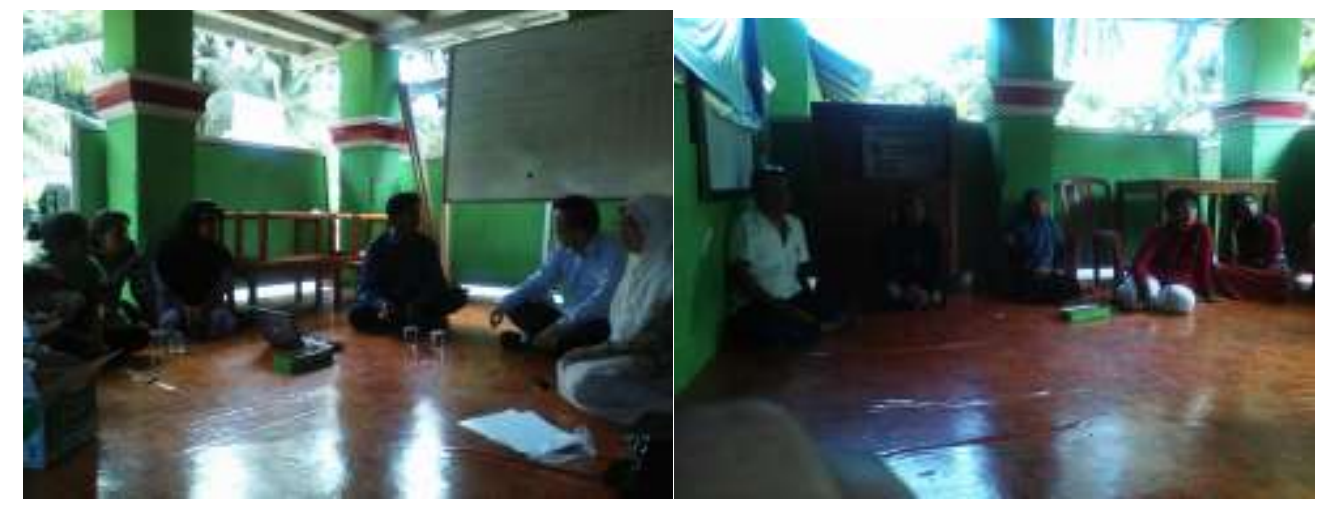

Gambar 6. Kegiatan Penyuluhan 


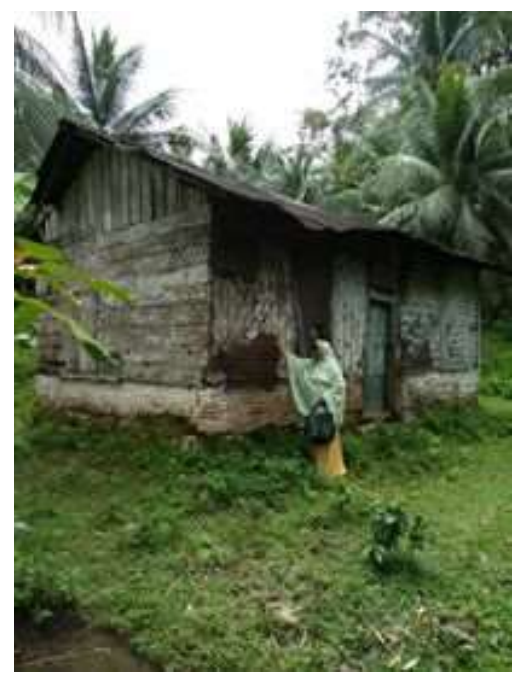

Gambar 7. Kondisi Awal Rumah
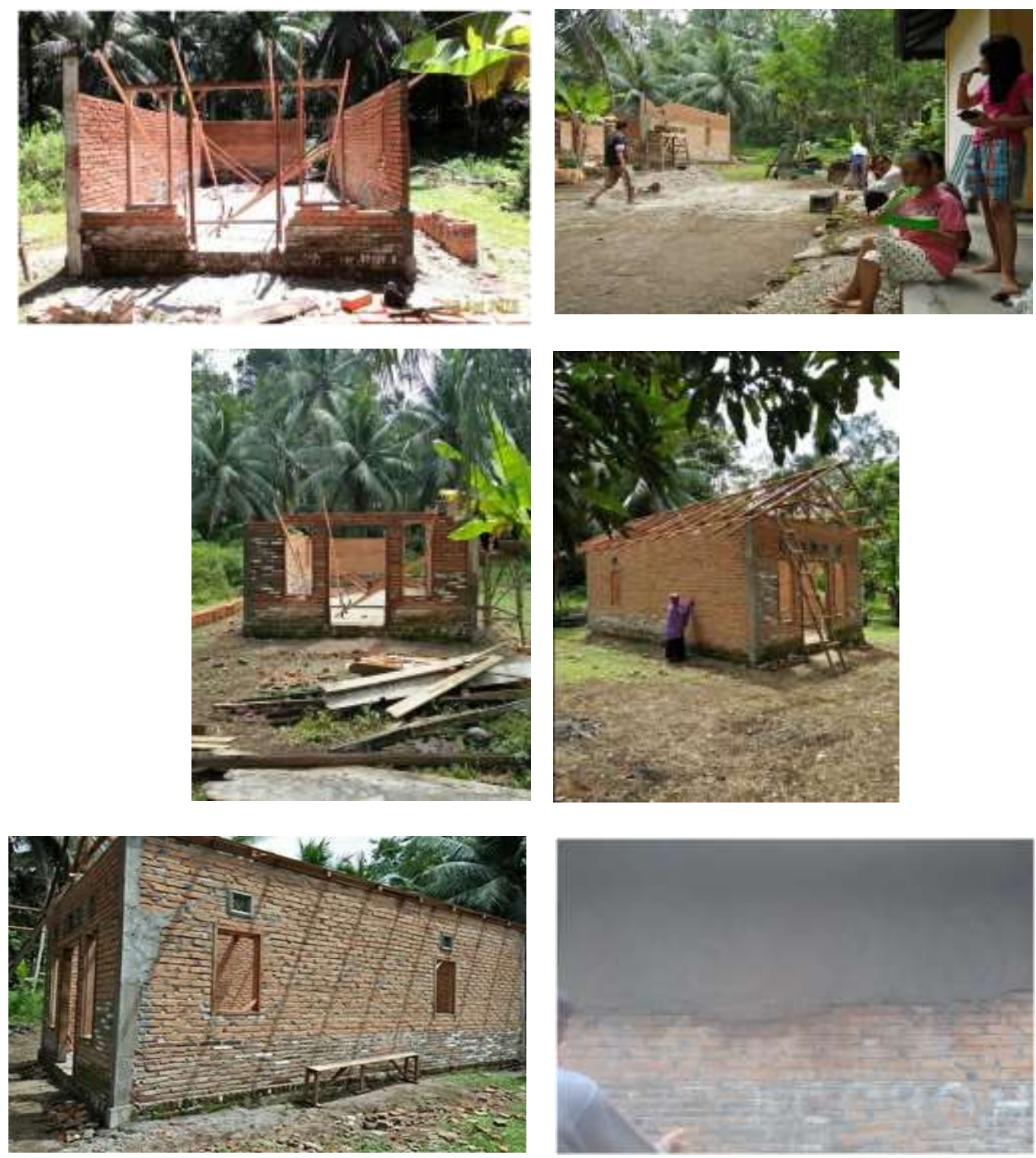

Gambar 8. Pelaksanaan Kegiatan 


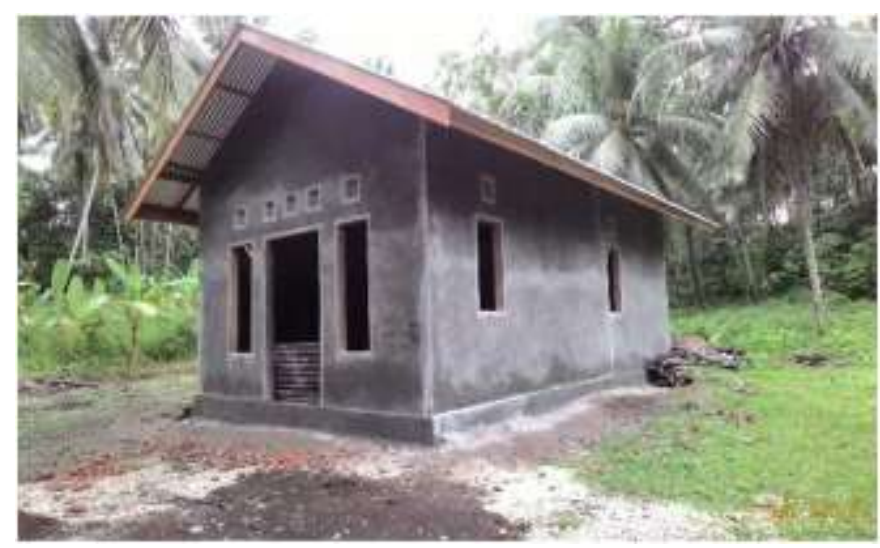

Gambar 9. Hasil

\section{KESIMPULAN}

Kegiatan pengabdian kepada masyarakat Nagari Koto Marapak Kabupaten Padang Pariaman, telah terlaksana dengan baik. Tujuan dari kegiatan ini telah tercapai yaitu perbaikan rumah masyarakat dari rumah yang tidak layak menjadi rumah layak dan mempunyai perkuatan terhadap gempa yaitu dengan memasang pelapis dinding menggunakan kawat ayam.

Disamping itu masyarakat juga termotivasi untuk selalu menambah pengetahuan mereka. Hal ini terlihat pada saat sosialisasi dan penyuluhan dimana masyarakat sangat antusias dalam bertanya dan menunjukkan keingintahuan yang besar.

Hasil pengabdian masyarakat ini disarankan untuk ditindaklanjuti oleh pemuka masyarakat dan pemerintah setempat agar lebih diketahui masyarakat luas.

\section{UCAPAN TERIMA KASIH}

Penulis mengucapkan terima kasih kepada DIPA Politeknik Negeri Padang yang telah memberi dukungan financial terhadap pengabdian ini.

\section{DAFTAR PUSTAKA}

Boen, T., 2005, Membangun Rumah Tembokan Tahan Gempa.

Boen,T.2012, Buku Panduan Perbaikan dan Perkuatan Bangunan Tembokan Sederhana, WSSI, JICA.

Hadibroto Bambang, 2018, Perbaikan dan Perkuatan Bangunan Sederhana Akibat Gempa, Jurnal Education Building Volume 4, Nomor 1, Universitas Negeri Medan.

Harris Pradono Mulyo, 2019, Kajian Penerapan Standar Tahan Gempa pada Pemeriksaan Struktur Gedung Terbangun, Jurnal Alami, Vol 3, No.1 Pusat Teknologi Reduksi Risiko Bencana, Kedeputian Bidang Teknologi Pengembangan Alam, Badan Pengkajian dan Penerapan Teknologi.

http://www.hyogo.uncrd.or.jp/school\%20project/retrofitting/indonesia_padasuka.pdf http://herudahnur.wordpress.com/2011/11/17/retrofiting-bangunan-kokoh-biaya-murah/ Mirani, Z, 2014, Perkuatan Bangunan Rumah Tinggal Sederhana terhadap Gempa Bumi, Jurnal Rekayasa Sipil Volume XI, Nomor 1, April 2014, ISSN 1858-3695, Politeknik Negeri Padang.

Prihatmaji Yulianto, 2013, Penyuluhan Bangunan Rumah Tahan Gempa sebagai Optimalisasi Mitigasi Gempa B Bumi, Jurnal Inovasi dan Kewirausahaan Vol 2, No.3 Universitas Islam Indonesia. 
Setiabudi Bawono Adi, 2016, Studi Kerentanan Bangunan Akibat Gempa : Studi Kasus Perumahan di Bantul, Jurnal Ilmiah Semesta Teknika Vol.19, No.1, 90-97.

Sulendra Ketut I, 2011, Evaluasi dan Tindakan Pengurangan Kerusakan Bangunan berdasarkan Peta Zonasi Gempa tahun 2010, Jurnal Infrastruktur Vol 1, No.2, Universitas Tadulako.

Suprianti Fepy, 2009, Studi Mitigasi Gempa di Bengkulu dengan Membangun Rumah Tahan Gempa, Jurnal Teknik Sipil Inersia Vol 1, No.1 Universitas Bengkulu.

UGM, SNS, 2009, Japan Platform, Panduan Perbaikan dan Perkuatan Rumah Tinggal Pasangan Bata agar Aman terhadap Gempa.

Zaidir dkk, 2018, Perbaikan dan Perkuatan Bangunan Pasca Gempa Sumatera Barat tahun 2009, Prosiding PIT ke-5 Riset Kebencanaan IABI Universitas Andalas.

Zulfiar Heri M dkk, 2014, Identifikasi Faktor Dominan Penyebab Kerentanan Bangunan di Daerah Rawan Gempa, Provinsi Sumatera Barat. Jurnal Ilmiah Semesta Teknika Vol. 17, No.2, 116125. 